\title{
Full-Scale/Model Test Comparisons to Validate the Traditional ABL Wind Tunnel Simulation Technique: A Literature Review
}

\author{
X.X. Cheng ${ }^{1}$, J. Dong ${ }^{1, *}$, Y. Peng ${ }^{1}$, L. Zhao ${ }^{2}$ and Y.J. Ge ${ }^{2}$ \\ 1 College of Civil Engineering, Nanjing Tech University, Puzhu South Road 30\#, Nanjing 211816, China; \\ cxx_njut@hotmail.com (X.X.C.); yang.peng@njtech.edu.cn (Y.P.) \\ 2 State Key Laboratory for Disaster Reduction in Civil Engineering, Tongji University, Shanghai, China; \\ zhaolin@tongji.edu.cn (L.Z.); yaojunge@tongji.edu.cn (Y.J.G.) \\ * Correspondence: dongjun@njtech.edu.cn
}

\begin{abstract}
Full-scale/model test comparison studies to validate the traditional atmospheric boundary layer $(\mathrm{ABL})$ wind tunnel simulation technique are reviewed. According to the literature review, notable discrepancies between full-scale measurement results and model test results were observed by most performed comparison studies, but the causes of the observed discrepancies were not revealed in a scientific way by those studies. In this regard, a new research scheme for future full-scale/model test comparison studies is proposed in this article, which utilizes the multiple-fan actively controlled wind tunnel simulation technique. With the new research scheme, future full-scale/model test comparison studies are expected to reasonably disclose the main problems with the traditional $\mathrm{ABL}$ wind tunnel simulation technique, and the technique can be improved correspondingly.
\end{abstract}

Keywords: comparison study; full-scale measurement; wind tunnel model test; multiple-fan actively controlled wind tunnel; research scheme

\section{Introduction}

As a mature technique applied in aviation industry, the wind tunnel model test was introduced into the field of wind-engineering research and design in 1960s. After Jensen [1] proposed that the flow field simulated in the wind tunnel should be similar to the actual atmospheric boundary layer (ABL) flow field for wind-engineering model tests, simulating ABL has become an indispensable test procedure. To fulfill the task of simulating realistic ABL turbulent flow fields in the wind tunnel, passive simulation devices, including spires, roughness elements, grids and barriers, can jointly be used. It has been found that the target flow fields can be obtained by adjusting the position and the number of some devices placed in the beginning of the wind tunnel [2,3]. During the past 50 years, most scientific researches and engineering practices made by the wind-engineering community utilized the traditional $\mathrm{ABL}$ wind tunnel simulation technique. With this technique, theoretical achievements were made, and numerous engineering structures' safety against extreme wind events was ensured. 
As a simulation technique, the reliability of ABL wind tunnel model tests inevitably drew the attention of the wind-engineering community. Since the traditional ABL wind tunnel simulation technique came into being, hundreds of studies are devoted to the validation of this simulation technique by comparing model test results with the corresponding full-scale measurement results, and almost all types of engineering structures have been involved in those comparison studies. It is obvious that the full-scale/model test comparison is the most common practice for validating the traditional ABL wind tunnel simulation technique, which is basically supported by the whole wind-engineering community. The only converse opinion that can be found in literatures was held by Dalgliesh [4], who thought that full-scale measurements were inherent less accurate and deterministic than wind tunnel experiments they were supposed to validate, so full-scale/model test comparison studies had limitations.

Up to today, most full-scale/model test comparison studies for validating the traditional ABL wind tunnel simulation technique have been disseminated to the profession by literatures. Those comparison studies are usually comparable with regard to the engineering background, the design and implementation of the experiment, the experimental results, the interpretation of results, etc., although differences among them are discernable as well. If these comparison studies are reviewed effectively, a clear outline of the field can emerge for prompt learning, and useful experiences and neat practices can be summarized to guide future researches, and profound perspectives can be conceived to understand the matter of science in an all-rounded and thorough way. These things may ultimately result in the promotion of the traditional $\mathrm{ABL}$ wind tunnel simulation technique through endeavors correctly made by the wind-engineering community. However, to the writers' knowledge, related literatures were not summarized before.

In view of this narrative, a literature review on full-scale/model test comparison studies is performed following a brief introduction of the traditional $\mathrm{ABL}$ wind tunnel simulation technique in this article first, which lays emphasis on generalizing full-scale/model test discrepancies observed by different comparison studies and related researchers' explanations for those discrepancies. Then, based on the observation that no performed full-scale/model test comparison study revealed the causes of the discrepancies in a scientific way, the multiple-fan actively controlled wind tunnel simulation technique is introduced into full-scale/model test comparison studies.

\section{The Traditional ABL Wind Tunnel Simulation Technique}

According to Dyrbye and Hansen [5], before Jensen's model law was published in the mid 1950s, the wind tunnels used were often aeronautical tunnels with short working sections. They were converted for civil engineering applications by adding passive devices, such as grids, barriers, fences and spires, in the test section entrance in order to generate turbulence. The floor of the test section, which is usually on the order of $5 \mathrm{~m}$ long, is covered with roughness elements to generate thick ABL. However, turbulence generated in these tunnels does not meet the basic similarity requirements necessary to obtain realistic test results for structures situated in the ABL. Jensen's model law changed wind tunnel practice fundamentally. Since the model law was published, ABL wind tunnels with long working sections have been constructed. According to Simiu and Scanlan [6], in long wind tunnels, a boundary layer with a typical depth of 0.5 to $1 \mathrm{~m}$ develops naturally over a rough floor of the order of 20 to $30 \mathrm{~m}$ in length. The height of most tunnels may be adjusted to increase slightly with position downstream. The purpose of such an adjustment is to achieve a 
zero pressure gradient stream, which would otherwise not be obtained, owing to energy losses associated with flow friction at the walls and with internal friction due to turbulence. Atmospheric turbulence simulations in long wind tunnels are probably the best that can be achieved at present. However, similarity between the turbulence in the laboratory flow and in the realistic ABL is generally not achieved even when passive devices are not used. When passive devices are used, the lack of similarity becomes stronger.

For model tests, simulation occurs at reduced geometric scale for obvious reasons of economy and convenience. According to Simiu and Scanlan [6], the question of scale opens up the whole area of physical similitude and the necessary underlying theory, which places emphasis on a set of dimensionless numbers and similarity criteria applicable to both flow and test models of structures placed in it. With characteristics of the target flow and scale factors for similitude established, it soon becomes apparent that certain of the model criteria established for similarity cannot in fact be satisfied under typical everyday test conditions. The wind tunnel modeler is thus launched upon a series of inevitable compromises that render his task complex, revealing it as an art of both performance and interpretation rather than an exact science.

Procedures used in wind tunnel model tests vary widely depending on particular objectives and available resources. A number of commonly used tests are [5]:

(1) Tests of local pressures using scaled static models with pressure taps, whose typical scales are of the order of 1:100 to 1:500. Mean and fluctuating pressures are often measured by connecting the pressure taps on the model with pressure transducers using thin vinyl tubing. The distortion of pressure fluctuations caused by the long tubes may be corrected using Fourier transform techniques. Alternatively, tubes giving low distortion up to high frequencies of several hundred hertz may be used in the tests. The fluctuating pressures measured in the wind tunnel are used to calculate the characteristic pressure and suction at each point of the structure.

(2) Tests of area wind loads using pressure models, whose typical scales are of the order of 1:100 to 1:500. Simultaneous measurement of several fluctuating pressures facilitate that the fluctuating area wind load can be determined by adding linear combinations of the pressures measured. Each pressure is weighed according to its influence on the actual loading in question. Pressures measured along a simply supported model beam, for instance, could be used to estimate reaction forces and bending moments. The response is estimated by appropriate linear pressure combinations based on the influence functions related to the response considered.

(3) Direct measurements of overall wind loads, whose typical scales are of the order of 1:100 to 1:500. The model is fixed to a base balance measuring the overall wind load acting on the model. Some balances measure all six load components, i.e., three forces and three moments; other balances measure only some of the load components. Specifically designed high-frequency base balances may be used to measure the fluctuating overall wind load on the model without significant distortion from natural model vibrations. The models used in these tests should have a natural frequency in excess of the most significant wind loading frequencies. Light and stiff models are asked for, e.g., models constructed by foam.

(4) Section model tests, whose typical scales are of the order of 1:50 to 1:100. Section model tests are used to determine the aerodynamic data, e.g., the aerodynamic derivatives and the flutter parameters. Preliminary investigations of the geometric shape of bridge deck using 
section model tests can be conducted in smooth flow. However, this practice of not simulating the turbulent flow is an exception rather than the rule [6].

(5) Aero-elastic tests using dynamically scaled models of buildings, bridges, etc., whose typical scales are of the order of 1:100 to 1:300. In aero-elastic tests, the model movements should be affine with the movements of the full-scale structure, and the natural frequencies and structural damping should be simulated in the test. The construction of aero-elastic models is often time consuming due to the demand of accurate scaling of the many significant modes contributing to the wind-induced structural behavior.

\section{Performed Full-Scale/Model Test Comparison Studies}

Since the traditional ABL wind tunnel simulation technique was developed, hundreds of studies focus on the validation of the simulation technique by comparing model test results with the corresponding full-scale measurement results under the engineering backgrounds of low-rise buildings, high-rise buildings, bridges, large-span structures, towers, etc., which are respectively reviewed in this portion of study.

\subsection{Low-Rise Buildings}

A large number of full-scale measurement campaigns for wind effects on low-rise buildings were launched in the last four decades [7]. In the early 1970s, the BRE (Building Research Establishment) in the UK commenced a program of full-scale measurements on a specially constructed experimental building of two stories in Aylesbury, England. In the late 1980s, another famous full-scale experiment on a low-rise building was set up in Lubbock, TX, USA. Almost at the same time, a new full-scale experiment was commenced in Silsoe, UK, which utilized a steel frame building with variable eave types. At the beginning of twentieth century, a $6 \mathrm{~m}$ cube was constructed at the Silsoe Research Institute in an open country exposed position. During the late 2000s, the researchers from Hunan University in China envisaged the idea of removable low-rise buildings and successfully measured wind effects on low-rise buildings during typhoon using a removable house. These full-scale measurement campaigns permit researchers to make appropriate comparisons with wind tunnel measured data.

Marshall [8] compared the wind pressures measured on a single-family dwelling with results obtained from a 1:50 scale model placed in a turbulent boundary layer. It was shown that the pressure spectra and the coherence of surface pressures obtained from full scale and model scale experiments agreed with each other, but the fluctuating pressure coefficients from the wind tunnel model were consistently low. Apperley et al. [9] modeled the two-storey house at Aylesbury, England built by the BRE for the full-scale measurement of wind pressures at 1:500 scale in a boundary layer wind tunnel. Surface pressure measurements measured in the wind tunnel were compared with full-scale data for various wall and roof locations. For the model terrain best modeling full-scale conditions, the results showed agreement. In particular, for winds normal to a face, agreement between the wind tunnel experiment and the full-scale experiment was as good as between two similar full-scale runs obtained on different days. However, the model test results had been found to be sensitive to local roughness elements in the upstream terrain. It was suggested that the apparent roughness length simulated in the wind tunnel was obviously limited in its ability to characterize the local roughness near the measuring site, and the traditionally used similarity parameter was probably not sufficient to ensure similarity. Richardson and Surry [10] compared 
full-scale surface pressures measured on a range of agricultural buildings with wind tunnel test results using 1:100 scale models. Mean, root-mean-square (rms), maximum and minimum pressure distributions obtained from the two experiments at mid-building-length for winds perpendicular to the ridge line were compared. The comparison showed that very good agreement was possible. However, where separation and recirculation occurred on the windward roof slope, the model-scale significantly underestimated the suctions, and this effect appeared to be roof pitch dependent. Tieleman [11] made model/full scale comparisons of the mean and fluctuating pressures on surface-mounted prisms placed in a variety of turbulent boundary layers to evaluate the effect of the small spires placed directly upstream of the model location on pressure coefficients in comparison with the conventional spire-roughness simulation method. Tieleman [12] showed measurements on the full-scale Texas Tech University experimental building $[13,14]$ and Colorado State University and University of Western Ontario wind tunnel models of that building. Wind tunnel measurements were seen to be acceptable for the wall pressures but quite inadequate for the roof corner. Richardson and Blackmore [15] compared the model-scale wind pressures for Silsoe Structures Building to full-scale data. It was found that, for transverse winds, both sets of data compared well. However, it was found that model-scale measurements underestimated the mean pressure coefficient for cornering winds. Dalley [16] compared the surface pressure measured on a low-rise building model in the wind tunnel to the benchmark full-scale data taken at Silsoe Research Institute. Comparisons between model and full-scale surface pressure spectra at two tapping positions were made. Differences were identified, which might be linked to the discrepancies of the mean pressure. Geurts [17] compared the full-scale and the wind-tunnel measurements of wind-induced pressures on windward and leeward side of a building in built-up terrain. The wind velocity spectrum in the wind tunnel was shifted towards higher reduced frequencies, compared to the full-scale data. The full-scale pressure spectra attenuated faster than velocity spectra in full-scale. In the wind tunnel, this was not observed. The coherence of pressures was identical in full scale and wind tunnel in many cases, except one point in the windward façade. Hoxey et al. [18] compared the detailed wind pressures measured on a low-rise building at full scale and those obtained on a wind tunnel model, and found that differences existed at the separated flow region on the windward roof slope of the building. Richardson et al. [19] obtained two independent sets of full-scale wind pressures on Silsoe Structures Building in two configurations and compared them with those from two 1:100 scale measurement programs conducted in wind tunnels. It was found that by implementing certain wind tunnel procedures, good predictions of full-scale mean pressure coefficients could be obtained. However, areas of high negative pressure still tended to be underestimated in wind tunnel measurements. Hoxey et al. [20] compared surface pressures measured at both full scale and model scale on a conventional low-rise pitch-roofed building, and found differences in the separation flow at the windward eaves of the building. Richards et al. [21] made detailed measurements of surface pressure on a $6 \mathrm{~m}$ cube constructed at Silsoe Research Institute in an open country exposed position and measurements of the wind velocities in the region around the cube. Mean pressure coefficient data were compared with published wind tunnel data. With the wind perpendicular to one face, it was shown that there was general agreement on the windward wall pressures between the full-scale and the wind tunnels. However, the roof and leeward wall pressures appeared to be different between full-scale and wind tunnel results. Richards and Hoxey [22] studied the effects of reattachment length on the pressure distribution on a $6 \mathrm{~m}$ cube by 
full-scale measurements, and found that the effects could not account for the differences between the field data and typical wind tunnel results. According to Kasperski and Hoxey [23], some studies of aerodynamic coefficients from wind tunnel experiments showed that the extremes of some local pressures and some global forces followed a type III distribution, and it was found that a type III distribution could be fitted to the full-scale data from the $6 \mathrm{~m}$ Silsoe cube. Liu et al. [24] presented a comparison of the full-scale pressure coefficient from one single-family home, which experienced sustained hurricane force winds, with the results of wind tunnel experiments on a 1:50 scale model of that home. It was determined that the wind tunnel and full-scale mean and rms pressure coefficients matched very closely at almost every monitored location on the roof, while the peak negative pressure coefficients in the wind tunnel study generally underestimated the full-scale values. Huang et al. [7] constructed a wind-engineering research field laboratory, which consisted of a full-scale low-rise building with adjustable roof pitch for wind pressures on the structure and two anemometer towers for the characteristics of near-ground wind field. Two pieces of ten-minute-length wind pressure time-histories obtained at 0 degree and 20 degree roof pitches were analyzed to compare with those of a wind tunnel test on a rigid model of 1:30 scale. The results showed that the mean and fluctuating wind pressure distributions for the two experiments were similar.

\subsection{High-Rise Buildings}

From early 1960s, Dalgliesh et al. started to measure wind effects on high-rise buildings located in downtown areas in Canada under strong winds, and compare those full-scale measurement results to the corresponding model test results. Dalgliesh et al. [25] took wind pressure records ranging from 15 minutes to about one hour from twelve simultaneously recorded pressure transducers located at two levels in a $400 \mathrm{ft}$ high office building in downtown Montreal. The full-scale mean pressures, variances, spectral functions and cross-spectral functions were determined. Comparing the full-scale measurement results to the preliminary work of wind tunnel measurements in cooperation with the University of Western Ontario, it was indicated that successful simulation of the basic statistical properties of wind pressure fluctuations could be obtained through the use of model complexes in a boundary layer type of wind tunnel. Dalgliesh [26] made wind pressure measurements over a 4-year period on a 34-story building in downtown Montreal for checking and improving wind tunnel techniques of modeling flow characteristics of wind and aerodynamic behavior of buildings. Comparisons were made on the basis of mean pressures, rms pressures, power spectra and the correlation between selected pairs of pressures at various points on the building. Examples were found of excellent agreement in almost all respects, but for some wind directions the comparisons gave unsatisfactory correlations. Dalgliesh [27] made simultaneous surface wind pressure measurements at 32 points on a 57 -storey office tower in Toronto. Mean and rms pressures were recorded, and pressure coefficients referred to the free stream dynamic pressure at $286 \mathrm{~m}$ were computed for comparison with wind tunnel test information. The results indicated satisfactory agreement between full-scale and model measurements of mean pressures, but it was too early to say the same for rms coefficients. Dalgliesh and Rainer [28] presented measurements of wind-induced movements in the Bank of Commerce Building in Toronto, Canada. They concluded with a preliminary assessment of the agreement between measured building movements and those predicted based on wind tunnel tests that wind tunnel data, which had been adjusted for building frequency, correlated well with the measured data. Dalgliesh et al. 
[29] compared full-scale pressure coefficients from a 57-storey building in Toronto and wind tunnel results from test in a $9 \mathrm{~m}$ by $9 \mathrm{~m}$ wind tunnel. Good agreement was demonstrated where sufficient full-scale data existed. Dalgliesh [4] reviewed the main findings of the earlier comparisons of full-scale measurements and wind tunnel tests for the Commerce Court Tower in Toronto, Canada, and supplemented them with new examples comparing the dynamic behavior of the building and an aero-elastic model. Comparisons suggested that because field observations were subjected to so many uncontrolled variables, there might be little hope of predicting the full-scale behaviors to within better than about 10 to 15 percent, even when the input data on which the model was based were accurate. Dalgliesh et al. [30] presented several years of observations of accelerations during moderate to high winds at the Commerce Court Tower. Full-scale and model observations of the standard deviation of acceleration correlated well for most wind directions.

From early 2000s, Li et al. seized many opportunities of typhoon passing south and southeast areas in China to measure typhoon characteristics and typhoon-induced responses of high-rise buildings. Full-scale measurement results were utilized to validate the wind tunnel model tests conducted at the high-rise buildings' design stages (mainly force balance model tests). Li et al. [31] continuously measured acceleration responses of Di Wang Tower during the passage of Typhoon Sally in 1996. It was found that the measured acceleration data were consistent with those obtained from the force balance model test. Li et al. [32] presented the field measurement results of structural responses of two super tall buildings during the passage of Typhoon Sally, i.e., Central Plaza Tower (374 m) in Hong Kong and Di Wang Tower (384 m) in Shenzhen, which were compared with the wind tunnel results. It was found by comparison that the differences between the accelerations measured on the location and those obtained in the wind tunnel were in the range of 4.0-12.5\% for the two super tall buildings. Li et al. [33] presented results of full-scale and wind tunnel experiments for wind effects on Jin Mao Tower. In the wind tunnel, mean and fluctuating forces acting on the building model were measured by a high-frequency force balance under suburban and urban boundary layer wind flows considering the isolated building case and the building with surroundings case. On the other hand, full-scale measurements of wind effects on Jin Mao Tower were conducted under typhoon conditions. The wind tunnel model test results were found to be in good agreement with the full-scale measurement results, illustrating that the wind tunnel model tests could provide satisfactory predictions of wind-induced vibrations of the super tall building under typhoon conditions. Li et al. [34] presented some results obtained by full-scale measurements of wind effects on Jin Mao Tower during the passage of Typhoon Rananim in August, 2004. Besides, a wind tunnel experiment was conducted to study wind effects on Jin Mao Tower using the force balance, which were compared with the full-scale measurement results. It was found that the acceleration data measured on the location were consistent with those from the model test, and the differences between the field measurement results and the wind tunnel data were $11.8 \%$ and $19.1 \%$ for two oncoming flow directions. Li et al. [35] presented results of wind characteristics and structural responses measured on four super-tall buildings, i.e., the Center (350m high) in Hong Kong, Di Wang Tower (384m high) in Shenzhen, CITIC Plaza Tower (391m high) in Guangzhou and Jin Mao Tower (421 m high) in Shanghai, during the passages of three typhoons. By comparing the full-scale measurement results with the wind tunnel results, it was found that most acceleration data measured on the location were consistent with those obtained from the model tests, although the model test results were generally conservative. The differences 
between the field measurement results and the wind tunnel data were in the range of 9.3-19.1\% for the four super-tall buildings. Fu et al. [36] presented the boundary layer wind characteristics and the corresponding wind-induced responses of two super-tall buildings measured on the location. By comparing the full-scale measurement results with the wind tunnel test data, it was found that the acceleration data measured on the location were consistent with those obtained from the model tests, although the model test results were generally conservative. The differences between the field measurement results and the wind tunnel data were in the range of 12.4-16.5\% for the two super-tall buildings. Fu et al. [37] conducted field measurements of the oncoming flow and wind effects on Guangzhou West Tower when Typhoon Megi affecting this super tall building on October 22, 2010. Beside the wind data and the wind-induced acceleration of the structure, the wind-induced pressures on the building surface were measured to evaluate the characteristics of the cladding wind loads. The measured wind-induced accelerations and wind pressures were further compared with those obtained from wind tunnel model tests. It was found that the accelerations obtained from force balance model tests were basically in good agreement with those from field measurements, and slight differences were observed between the mean values of wind-induced pressures obtained from the two experiments. Yi and Li [38] presented results of full-scale measurements and the model test for wind effects on a super-tall building with a height of $420 \mathrm{~m}$ in Hong Kong. By comparing the model test results with the full-scale measurement results, it was shown that the wind tunnel model test could provide reasonable predictions of the realistic resonant responses of the building, but it could not predict the realistic background responses well.

Different from the comparison studies focusing on wind effects on external building surfaces and wind-induced structural responses, Kato et al. [39] investigated the characteristics of wind-induced internal pressures in a high-rise building. Full-scale measurements were taken using absolute pressure meters, and the internal mean pressure coefficients obtained from full-scale measurements were about -0.26 which were constant over the building's height. The mean internal pressure coefficients estimated using wind tunnel modeling were consistent with those obtained from the full-scale measurement. It was therefore inferred that the mean wind pressure coefficient obtained from the wind tunnel testing was sufficient for examining average internal pressures in buildings.

Literatures suggest that some advanced equipments were utilized in full-scale experiments. Lim et al. [40] examined the feasibility of using continuous-wave Doppler Lidars as opposed to traditional experimental instrumentations for flow measurements around full-scale buildings. The normalized mean velocities and the turbulence intensities measured around a full-size nominally cuboid building in suburban terrain were compared to results obtained from a 1:100 scaled wind tunnel test. The turbulence intensities obtained from the wind-tunnel experiments were 2-6\% higher than the nominal value of $14 \%$ measured in the full-scale testing.

\subsection{Bridges}

Many long-span bridges were equipped with structural health monitoring systems in recent years, which rendered good opportunities to study the realistic behaviors of these large structures under strong winds. However, limited researchers employed the data measured on the real structures to validate the model test predictions. Delaunay and Grillaud [41] carried out field measurements of the wind turbulence and the wind-induced response of a cable-stayed bridge to check the validity 
of the turbulence characteristics used for design based on wind tunnel studies and the previsions of the structural dynamic responses obtained by combining theoretical computations and taut-strip model experiments. It was found that both the turbulent wind characteristics in the wake of an upstream arch bridge measured on the location and the full-scale response of the cable-stayed bridge submitted to this particular excitation were in agreement with the results of earlier estimations. The main discrepancies concerned the predicted responses of the 2 nd and 3 rd vertical flexural modes which were lower than the full-scale ones. Frandsen [42] carried out full-scale measurements on the Great Belt East suspension bridge. Large amplitudes due to vortex-induced oscillations were measured, and lock-in observed. Pressures at the deck surface and accelerations were measured simultaneously for the first time. Pressure-acceleration correlations at and off lock-in were estimated. By comparing full-scale measurement results to model test results, it was found that limitations of conventional experimental methods for predicting the full-scale behavior were evident. $\mathrm{Xu}$ and $\mathrm{Zhu}$ [43] measured the wind velocities and analyzed structural responses of Tsing Ma Suspension Bridge in Hong Kong during Typhoon Sam in 1999. The skew wind characteristics surrounding the bridge, the modal damping ratios and acceleration responses of the bridge were obtained on the location. The buffeting responses of the bridge under skew winds during Typhoon Sam were then computed using the wind characteristics and modal damping ratios measured on the location and the aerodynamic coefficients and flutter derivatives of the bridge deck and tower obtained from the wind tunnel model test under skew winds. By comparing the computed acceleration responses of the bridge deck and the cables to those measured on the location, it was found that the agreement was good in general. Li et al. [44] monitored the wind-induced vibrations of a full-scale suspension bridge with a central span of $1650 \mathrm{~m}$. Thirty-seven vortex-induced vibration (VIV) events were observed. The VIVs from a section model test and those from the full-scale bridge were compared, and it was found that the vertical VIV amplitude of the section model was much lower than that from the field monitoring. Moreover, torsional VIVs appeared in the section model test, whereas it was not observed on the full-scale bridge.

\subsection{Other Structures}

Some full-scale/model test comparison studies used other structures as the engineering background, e.g., large-span structures and towers. Chen et al. [45] presented results of a combined study of full-scale measurements and wind tunnel model tests for an exhibition center. In the wind tunnel, wind-induced pressures were obtained on the roof of a 1:300 scale model under the suburban boundary layer wind flow. Full-scale measurements of winds and wind-induced structural responses of the structure were conducted during the passage of Typhoon Nuri. By comparison, it was found that the acceleration responses measured on the location were in good agreement with those obtained from model tests. Chen et al. [46] carried out full-scale measurements for wind-induced responses of a long-span cable-supported roof. At selected locations, the response power spectral density functions from full-scale measurements agreed qualitatively with those computed from the FE model of the structure where the wind load input was obtained from simultaneous pressure measurements in the wind tunnel, suggesting a validation of the wind tunnel based predictions. Pirner [47] presented the results of model and in situ measurements of the fluctuating wind pressures on a cooling tower. On the model, wind pressures were detected by means of two microphones at Reynolds number $(\mathrm{Re})=5.04 \times 10^{5}$, and 
the pressures in situ were obtained at $\mathrm{Re}=3.48-5.22 \times 10^{7}$. It was found that when certain conditions were preserved, the agreement between the two experiments was very good. In 2009, a full-scale measurement campaign for wind effects on a 167-meter high cooling tower located in Peng-cheng electric power station in China was launched by Cheng et al. [48]. Comparing the results obtained from full-scale measurements to those from wind tunnel model tests, Cheng et al. [49] found that the agreement of the static wind effects between the two experiments was good, but that of the dynamic wind effects was not satisfactory. Besides, Cheng et al. [50] found by comparison that the traditional model test was conservative for use with regard to the unfavorable spectral characteristics of wind-induced pressures on the tower model.

\subsection{Researchers' Explanations for the Observed Differences}

From the literature reviews presented above, most full-scale/model test comparison studies arrived at the conclusion that the discrepancies between the full-scale measurement results and the corresponding wind tunnel results were noticeable. Typical discrepancies were: (1) Mean and peak negative pressures at corners and separated flow regions on low-rise building roofs were underestimated in wind tunnels [7,12,18-20,24]; (2) Local fluctuating pressures attributable to vortex shedding on high-rise building models differed from those on the prototype [27]; (3) Aero-elastic model tests for high-rise buildings underestimated the dynamic structural responses in the intermediate-frequency range [4]; (4) Differences between rms accelerations measured on the location and those obtained from the force balance model test were in the range of $4-25 \%$ for high-rise buildings [32,34-37]; (5) Long-span bridges' vertical VIV amplitudes obtained using section models and full bridge aero-elastic models were much lower than those observed on the location $[42,44]$; (6) The pressure fluctuations measured on real structures followed non-Gaussian distributions, while the corresponding samples obtained from model tests followed Gaussian distribution [37,47,48,50]; (7) Model test results were conservative with respect to the spectral characteristics of wind-induced pressures measured on building models [17,50], since the normalized pressure spectra obtained in the wind tunnel were usually higher at high-frequency ranges than the full-scale values, and the coherences between pressure fluctuations tended to be stronger in the wind tunnel than at full scale. Taking a step forward, many related researchers explained the causes of the observed differences:

Low-rise buildings: Dalley [16] thought that the poor comparison between full-scale and model spectra over the eaves of the low-rise building probably indicated differences in the approaching flow between full-scale and wind tunnel experiments. Hoxey et al. $[18,20]$ believed that bluff-body aerodynamics were Re sensitive, and the discrepancies observed were significant Re effects associated with the separated flow region on the windward roof slope of the low-rise building. Richardson et al. [19] supposed that the observation that areas of high negative pressure on the low-rise building roof tended to be underestimated in wind tunnel measurements related to the fact that viscous damping at model scale attenuated the magnitude of the pressure field in separated and vortex flows, which basically belonged to Re effects. Richards et al. [21] believed that both approach flow conditions and scale, i.e., velocity profile, turbulence and Re, should be responsible for the discrepancies. Richards and Hoxey [22] briefly considered the effects of reattachment length on the pressure distribution, but it was shown that the effects did not account for the differences between the Silsoe field data and typical wind tunnel results. They suggested that the pressure differences should be related to Re which was not associated with changes in 
reattachment length. Huang et al. [7] thought that the evident gap for magnitudes of mean and fluctuating pressure coefficients between field measurement and wind tunnel model test results for the low-rise building was probably caused by inadequate simulation of turbulence intensities in the wind tunnel, small-scale turbulence content in the wind tunnel, inaccurate details of the structural model, different stationary state of incoming flows, Re effects and Jensen number effects.

High-rise buildings: Dalgliesh [26] supposed that the discrepancies were involved in making field measurements on high-rise buildings and in comparing them with wind tunnel measurements: (a) difficulty of establishing a static reference pressure and its relation to the static pressure in the wind tunnel; (b) inadequacy of wind velocity information; (c) lack of stationarity and homogeneity of the velocity field as compared with the wind tunnel situation. Dalgliesh [27] thought that reasons for the discrepancy between full-scale measurement and model test results for a high-rise building were that full-scale winds were not frequent enough or strong enough to provide sufficiently reliable rms data, and unsteadiness existed in the full-scale wind direction. Dalgliesh [4] supposed that full-scale experiments were inherently less deterministic and accurate than the wind tunnel experiments they were supposed to validate, since field observations were subjected to so many uncontrolled variables. Lim et al. [40] thought that the discrepancy between full-scale measurement and model test results for a high-rise building was mainly due to the relatively low sampling frequency of the Lidar combined with the spatial averaging of the data over a relatively large area.

Bridges: Delaunay and Grillaud [41] supposed that the discrepancy between full-scale measurement and model test results for the bridge was a result of the improvements of the bridge between earlier design stages and the final project. Frandsen [42] thought that it was due to the scaling effects. Li et al. [44] attributed the discrepancy between full-scale measurement and model test results for the suspension bridge to Re effects and the flow pattern difference.

Other structures: Chen et al. [46] supposed that the difference of the stadium's dynamic responses obtained from full-scale measurements and the prediction utilizing both wind tunnel model tests and finite element calculations might be attributed to inaccuracy in full-scale measurements, the inaccurate wind tunnel modeling of wind loads on the roof of the stadium, the difference in the approaching flow angle, the mismatch of the turbulence intensity and the turbulence scale between full-scale and wind tunnel experiments, the damping and limitations in the finite element model of the stadium. Cheng et al. [49] thought that the causes of the discrepancy between the full-scale measurement and the model test results for Peng-cheng cooling tower probably were: (1) the static reference pressure established for the full-scale measurement might hardly play the same role as the static pressure in the wind tunnel; (2) the full-scale velocity field lacked stationarity and homogeneity as compared with the wind tunnel situation; (3) simulation of large-scale turbulence content in $\mathrm{ABL}$ in the wind tunnel was inadequate.

\section{A New Research Scheme for Future Full-Scale/Model Test Comparison Studies}

\subsection{Similarity Problems with the Traditional ABL Wind Tunnel Simulation Technique}

The wind-engineering community currently comes to an agreement that three major similarity problems adversely affect the reliability of the traditional ABL wind tunnel simulation technique:

(1) Using passive simulation devices, turbulent flow characteristics of the whole realistic ABL 
flow field can hardly be completely simulated. Wind tunnel model tests consider empirical ABL flow characteristics presented in Codes of Practice and monographs as simulation targets, but it is found that the turbulent flow characteristics simulated in the wind tunnel deviate from the targets in many cases, which might cause significant effects (hereinafter referred to as turbulent flow characteristics effects) on model test results. For example, Pang [51] found that realistic mean wind speed profiles could be obtained using spires and roughness elements in the wind tunnel, and turbulence intensities and power spectral densities obtained below a certain height were accurate. However, the simulated turbulence intensities were sometimes lower than the simulation targets above a certain height, and the simulated power spectral densities might become unrealistic when the height was increased. Besides, the simulated turbulence integral scale decreased with the increase in height, which disagreed with the truth. Similar conclusions were reached by Farell and Iyengar [52] according to physical experiments. To solve the similarity problem of turbulent flow characteristics effects, some researchers placed actively controlled devices in the beginning of the wind tunnel's working section to increase turbulence intensity and turbulence integral scale of the simulated flow. The employed actively controlled devices were vibrating grids [53] and active vanes [54-63];

(2) Re effects exist for wind tunnel model tests. The separation location for the flow around a bluff body without corners is extremely sensitive to Re. Since the Re for usual model tests is two orders of magnitude smaller than the Re in full scale, significant effects on model test results might be caused by the Re difference. Fortunately, a method has been used to reduce Re effects by sticking paper belts on the model and adjusting the incoming flow velocity in the wind tunnel, which is called high Re effects simulation. Through high Re effects simulation, main wind effects obtained in the wind tunnel can get close to the full-scale measurement results;

(3) The nonstationary feature of the realistic ABL winds cannot be simulated in the wind tunnel, which might causes significant effects (hereinafter referred to as nonstationarity effects) on model test results. According to Kareem and $\mathrm{Wu}$ [64], hurricanes, tornadoes, downbursts and gust fronts are nonstationary in nature and are often highly transient. Different from those extreme wind events, the common ABL winds are generally assumed to be stationary. Based on this assumption, the traditional ABL wind tunnels, which can only generate standard stationary flows, are widely used. In reality, realistic ABL winds lack stationarity as compared with those simulated in the traditional ABL wind tunnel [26], and nonstationarity of wind speed and unsteadiness of wind direction are often found for realistic ABL winds [48]. Although the nonstationarity of $\mathrm{ABL}$ winds might not be as strong as that for the extreme wind events, it makes the whole flow field hard to understand and causes significant effects on wind loads on structures submerged in the flow field [50]. The practice of disregarding the nonstationarity of realistic $\mathrm{ABL}$ winds in wind-engineering design and research is unreasonable. Unfortunately, nonstationarity can hardly be simulated in traditional ABL wind tunnels, and such an adverse effect should be mitigated by correcting the obtained model test results [18], rather than introducing additional model test procedures.

Summarizing researchers' explanations for the observed differences presented in Sec. 3.5., Richardson et al. [19], Hoxey et al. [18,20], Richards and Hoxey [22] attributed the observed full-scale/model test differences to Re effects; Marshall [8], Apperley et al. [9], Dalley [16] 
attributed the observed differences to turbulent flow characteristics effects; Richards et al. [21], Li et al. [44], Chen et al. [46] thought that both Re effects and turbulent flow characteristics effects existed; Dalgliesh [26], Cheng et al. [48,50] attributed the observed differences to nonstationarity effects; Huang et al. [7] believed that all three adverse effects existed.

\subsection{Limitations of the Performed Comparison Studies and a New Research Scheme}

It should be realized that researchers' explanations for the causes of the observed full-scale/model test differences presented in Sec. 3.5. are all subjective conjectures without in-depth scientific validations, and some of their explanations disagree with each other. In this regard, endeavors should be made in the future to reasonably understand the similarity problems with the traditional $\mathrm{ABL}$ wind tunnel simulation technique based on quantifiable data. In practice, Re effects, turbulent flow characteristics effects and nonstationarity effects should be individually quantified using a reasonable scientific method, and the relationships of those adverse effects should then be studied. Through these works, the most significant similarity problem with the traditional ABL wind tunnel simulation technique can be found, which finally results in an improvement of the simulation technique.

It should be noted that the limitation of the performed comparison studies in revealing the similarity problems with the simulation technique in a scientific way is mainly attributed to the difficulty of separating the mingled adverse effects under the conventional experimental condition. To this end, an effective research scheme for future full-scale/model test comparison studies is formulated based on the multiple-fan actively controlled wind tunnel simulation technique [65-70]. Following the below procedures, the new research scheme can reasonably separate the mingled adverse effects:

Step 1: Obtain the oncoming flow information and the corresponding wind effects on structures simultaneously on the location, and obtain wind effects on scaled models in the traditional ABL wind tunnel;

Step 2: Use the oncoming flow information measured on the location to simulate a highly-accurate stationary ABL flow field (flow field A) and a highly-realistic nonstationary ABL flow field (flow field B) in the multiple-fan actively controlled wind tunnel, and obtain wind effects on scaled models in the two flow fields. Flow field A and flow field B are simulated using same methods, i.e., power spectrum modification method or time-lag modification method [66]. However, the simulation targets for the two flow fields are different. The simulation targets for flow field $\mathrm{A}$ is profiles of the theoretical ABL turbulence parameters presented in Codes of Practice and monographs in the form of empirical formulae. Thus, flow field A can accurately reproduce the theoretical ABL turbulent flow characteristics, but it cannot reproduce the nonstationary feature of the realistic ABL winds. The simulation targets for flow field $\mathrm{B}$ are realistic wind velocity time-histories measured on the location at different heights. Thus, flow field $\mathrm{B}$ represents the realistic $\mathrm{ABL}$ with the nonstationary feature;

Step 3: Calculate structural responses to wind actions obtained in different flow fields. Both flow field $\mathrm{A}$ and the flow field simulated in the traditional ABL wind tunnel are stationary in nature. Thus, the usual time-history dynamic analysis and equivalent static wind load methods can be employed for calculation. However, both flow field B and the realistic flow field are of nonstationary feature. Thus, the calculation methods should be corrected to support the prediction of structural responses to nonstationary wind excitations; 
Step 4: Compare wind-induced structural responses from full-scale measurements to those from the traditional wind tunnel model test to quantify the total discrepancies which contain the three adverse effects, i.e., Re effects, turbulent flow characteristics effects and nonstationarity effects, then employ wind-induced structural responses obtained from model tests conducted in flow field A and flow field B to separate the three adverse effects. Specifically, Re effects are quantified by comparing structural responses from full-scale measurements to those from the model test conducted in flow field B; nonstationarity effects are quantified by comparing structural responses from the model test conducted in flow field B to those from the model test conducted in flow field A; turbulent flow characteristics effects are quantified by comparing structural responses from the model test conducted in flow field A to those from the traditional wind tunnel model test;

Step 5: Compare different adverse effects and study their relationships to reveal the most significant influence to the reliability of the traditional ABL wind tunnel simulation technique.

The flowchart of the new research scheme is presented in Figure 1. As can be seen, the new research scheme largely relies on the multiple-fan actively controlled wind tunnel simulation technique. The capability of multiple-fan actively controlled wind tunnels in accurately simulating stationary and nonstationary ABL flow fields has been recognized by Nishi et al. [65-67], Nishi and Miyagi [68] and Cao et al. [69,70].

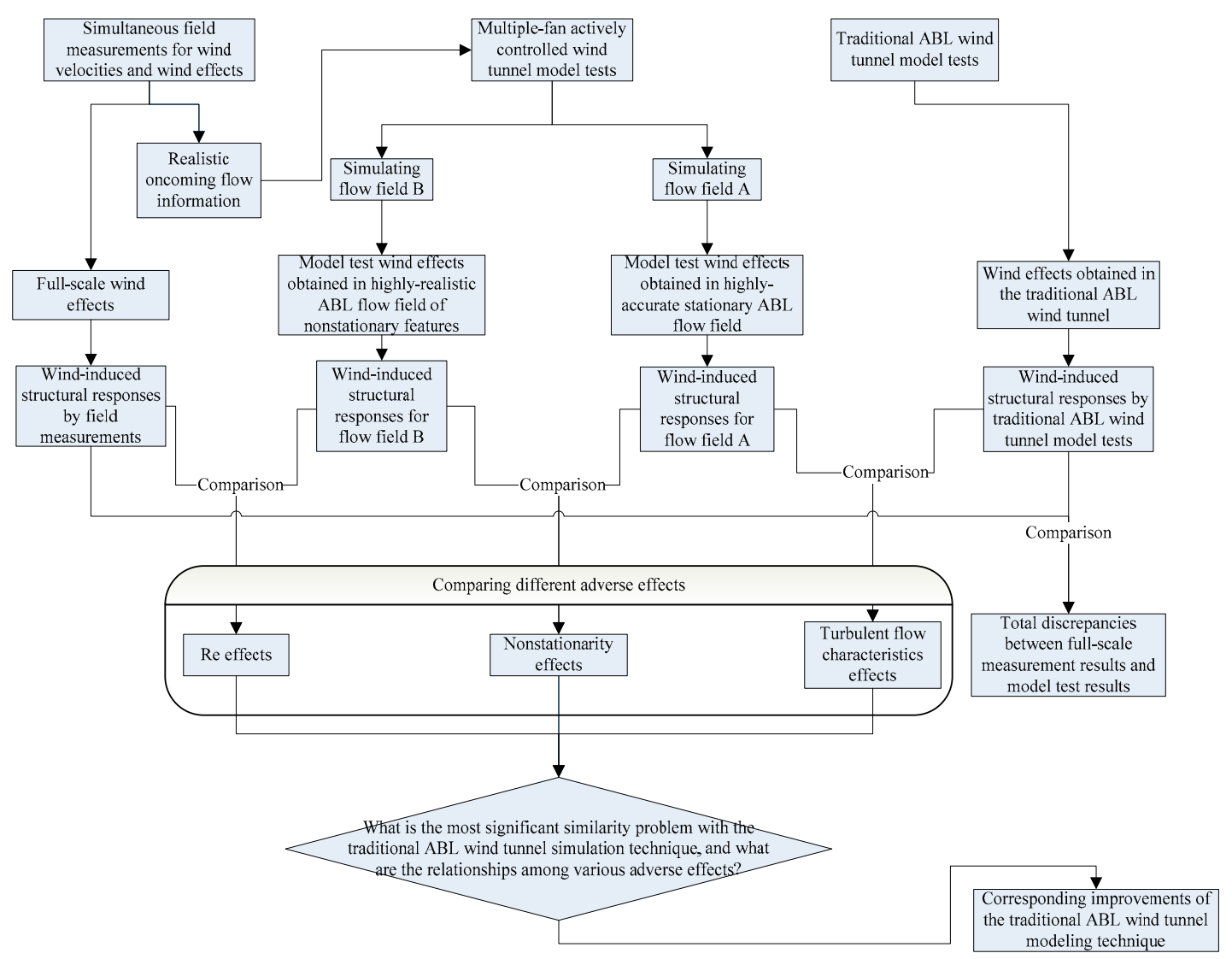

Figure 1. Flowchart of the new research scheme. 


\subsection{Multiple-Fan Actively Controlled Wind Tunnel Simulation Technique}

\subsubsection{Introduction of the Innovative Technique}

Since the concept of the actively controlled wind tunnel was proposed in 1970s, some researchers have realized flow control in wind tunnels, and mitigated some problems with the traditional ABL wind tunnel simulation technique, e.g., the low turbulence intensity and the small-scale turbulence content. However, they relied on actively controlled devices placed at the beginning of the traditional wind tunnel to adjust the simulated flow. Technically, their practice belongs to the semi-actively control. To this day, only researchers from Miyazaki University realized the actively controlled wind tunnel model test in its true sense. With the idea of flow production control, one 2-D and two 3-D multiple-fan actively controlled wind tunnels were built at Miyazaki University.

According to Cao et al. [70], one 3-D multiple-fan actively controlled wind tunnel at Miyazaki University is an open-circuit one with 99 fans of $270 \mathrm{~mm}$ in diameter at the front (see Figure 2). The fans are arranged in a 9 wide by 11 high matrix. The test section is $15.5 \mathrm{~m}$ long, $2.6 \mathrm{~m}$ wide and $1.8 \mathrm{~m}$ high. The fans are driven by AC servo-motors of high quality through a computer. The servo-motors can be controlled at different frequencies of up to approximately $25 \mathrm{~Hz}$, thus achieving fluctuating air flow in the test section. Since 99 fans can be programmed independently to deliver variable flows, phase shifts can be introduced among the fans, allowing transverse and vertical turbulence to be generated.

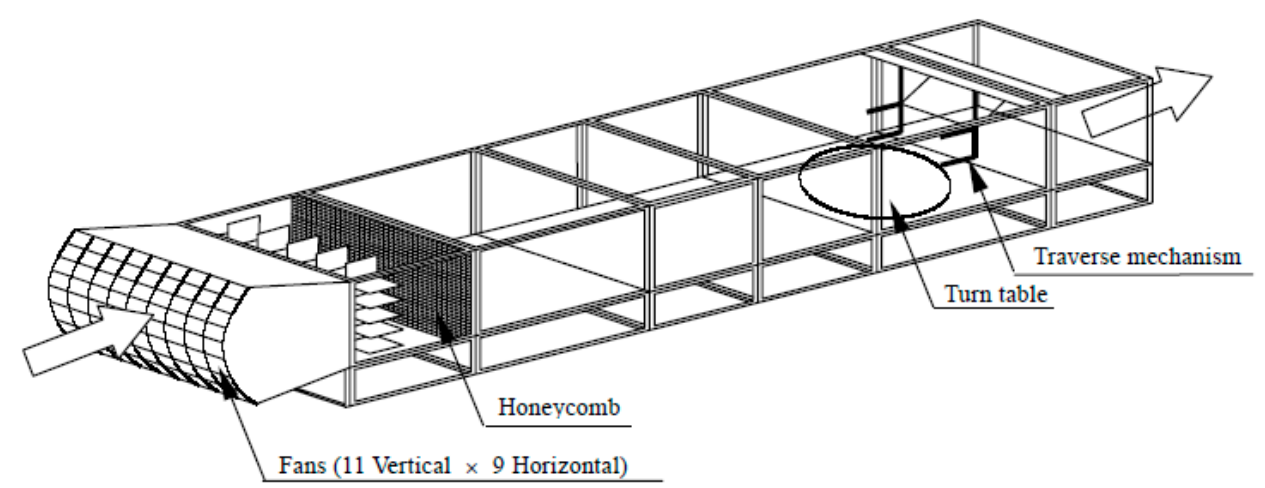

Figure 2. Schematic of a 3-D multiple-fan wind tunnel in Miyazaki University. Reprinted from [70].

Using power spectrum modification method (see Subsec. 4.3.2. for details) or time-lag modification method [66], highly accurate stationary ABL flow fields were simulated in multiple-fan wind tunnels, whose profiles of turbulence parameters and Re stress were identical with the targets [65-69]. Besides, by repeated modification of both power spectrum and phase of the input data to the fans, simulation of velocity histories with sharp velocity changes was also achieved by Cao et al. [70]. According to Cao et al. [70], the correlation coefficient between the target and generated velocity histories shown in Figure 3 is very high at 95.5\%. 


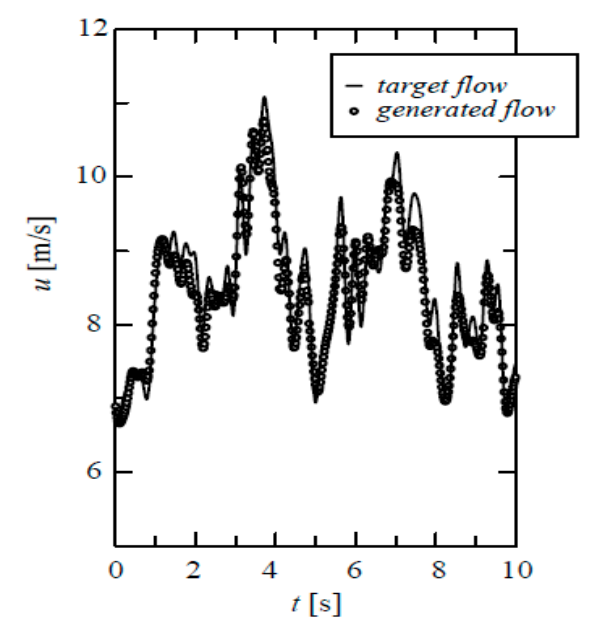

Figure 3. Simulation of velocity history with instantaneous abrupt velocity change in a 3-D multiple-fan wind tunnel. Reprinted from [70].

Although multiple-fan actively controlled wind tunnels are powerful facilities for simulating the highly-accurate stationary ABL flow field and the highly-realistic nonstationary ABL flow field, they were not widely employed for wind-engineering research and design, since it is costly to build these wind tunnels. Fortunately, a multiple-fan actively controlled wind tunnel is under construction at Tongji University in Shanghai, which is named TJ-5 wind tunnel (see Figure 4). As China's first multiple-fan actively controlled wind tunnel, TJ-5 has 120 independently controlled high sensitive fans arranged in a 10 wide by 12 high matrix. Its test section size is $1.8 \mathrm{~m} \times 1.5 \mathrm{~m}$, and its applied wind speed is in the range of $2.0 \sim 20 \mathrm{~m} / \mathrm{s}$. TJ-5 can be employed for future full-scale/model test comparison studies according to the new research scheme proposed in this article.

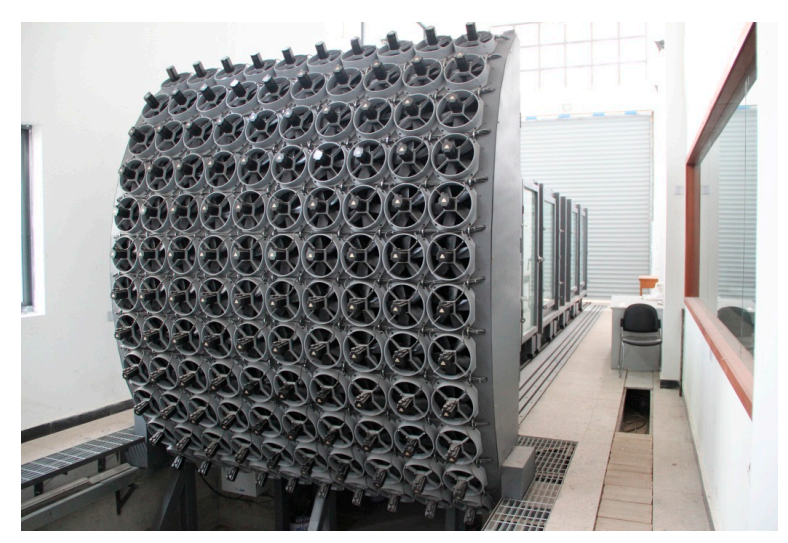

Figure 4. Exterior view of TJ-5 wind tunnel.

\subsubsection{Power Spectrum Modification Method}

Both flow field A (a highly-accurate stationary ABL flow field) and flow field B (a highly-realistic nonstationary ABL flow field) can be simulated in multiple-fan actively controlled wind tunnels using the power spectrum modification method proposed by Nishi et al. [66]. Using the power spectrum modification method, Cao et al. [70] reproduced velocity histories with sharp velocity changes at different heights in the 3-D multiple-fan actively controlled wind tunnel at Miyazaki 
University following three procedures:

(1) Transform the velocity history into voltage data proportionally, and input the data to the motors of the fans through AD converters. Because of the mechanical inertia of the rotating parts of the motor and because of the inertia of the air inside the tunnel, the velocity history generated cannot be the same as the voltage data history inputted to the motors;

(2) Modify the input data of the fans and drive the fans with new input data. Mathematically, the velocity history can be expanded to be the sum of a series in the frequency domain by fast Fourier transform (FFT). If the power spectrum and phase of the generated velocity history agree with the target ones well at each frequency, the generated velocity history will be very similar to the target one, and high correlation will be achieved between them. Thus, modification of the input data includes the modifications of power spectrum and phase. The methods are expressed in Eqns. (1) and (2):

$$
\begin{gathered}
S_{i}^{(k+1)}(f)=\frac{S_{t}(f)}{S_{m}^{(k)}(f)} \times S_{i}^{(k)}(f) \\
\phi_{i}^{(k+1)}(f)=\phi_{i}^{(k)}(f)+\left\{\phi_{t}(f)-\phi_{m}^{(k)}(f)\right\}
\end{gathered}
$$

where, $f$ is the frequency, $S_{m}^{(k)}(f), \phi_{m}^{(k)}(f)$ are the power spectrum and phase of the generated flow resulted from the input data with $S_{i}^{(k)}(f)$ and $\phi_{i}^{(k)}(f), S_{t}(f)$ and $\phi_{t}(f)$ are the target power spectrum and phase, and $\phi_{t}(f)$ is a random function. By doing inverse FFT with $S_{i}^{(k+1)}(f)$ and $\phi_{i}^{(k+1)}(f)$, new input data of the fans can be obtained;

(3) Repeat the modification of the input data of the fans until satisfied results are achieved. Modification of the input data should be repeated several times until satisfied results can be achieved.

Using the realistic wind velocity histories measured on the location as simulation targets, flow field $\mathrm{B}$ can be obtained by directly following the above mentioned procedures. If the power spectrum of the data input to the motors of the fans is modified, but the phase of the data is treated as the random variable in inverse FFT in procedure (2), flow field A can also be simulated using the method with the theoretical power spectrum at different heights according to Codes of Practice and monographs as simulation targets.

\section{Conclusions}

In this article, performed full-scale/model test comparison studies to validate the traditional ABL wind tunnel simulation technique are reviewed, whose engineering backgrounds are low-rise buildings, high-rise buildings, bridges, large-span structures, towers, etc. According to the literature review, most comparison studies observed notable discrepancies between the full-scale measurement results and the corresponding model test results. Although it is of practical significance to reveal the causes of the observed discrepancies in a scientific way, most studies only give some subjective explanations without scientific validations due to the limited experimental condition. However, future use of multiple-fan actively controlled wind tunnels will 
allow researchers to reasonably disclose all adverse effects related to the reliability of the traditional $\mathrm{ABL}$ wind tunnel simulation technique with quantifiable data. Thus, the true problems with the traditional $\mathrm{ABL}$ wind tunnel simulation technique can be found, and the technique can be improved correspondingly.

Acknowledgements: The authors gratefully acknowledge the supports of the National Natural Science Foundation of China (51178353 and 50978203), the National Key Basic Research Program of China (i.e., 973 Program) (2013CB036300), and China Postdoctoral Science Foundation.

Author Contributions: X.X. Cheng, J. Dong, Y. Peng, L. Zhao and Y.J. Ge conceived this article; X.X. Cheng wrote this article.

Conflicts of Interest: The authors declare no conflict of interest.

\section{References}

1. Jensen M (1958) The model-law for phenomena in natural wind. Ingenioren (Int. Ed.) 2: 121-128.

2. Lopes MFP, Gomes MG, and Ferreira JG (2008) Simulation of the atmospheric boundary layer for model testing in a short wind tunnel. Experimental Techniques 32(4): 36-43.

3. Huang P, Shi Z, Chen W, et al. (2001) Simulation method and measuring technology of atmospheric boundary layer. Journal of Tongji University 29(1): 40-44 (in Chinese).

4. Dalgliesh WA (1982) Comparison of model and full scale tests of the commerce court building in Toronto. Proceedings of the International Workshop on Wind Tunnel Modeling Criteria and Techniques in Civil Engineering Applications, Gaithersburg, Maryland.

5. Dyrbye C and Hansen SO (1997) Wind Loads on Structures. John Wiley \& Sons, New York.

6. Simiu E and Scanlan RH (1996) Wind Effects on Structures. John Wiley \& Sons, New York.

7. Huang P, Wang X, and Gu M (2012) Field experiments for wind loads on a low-rise building with adjustable pitch. International Journal of Distributed Sensor Networks Article ID 451879, 10 pages.

8. Marshall RD (1975) A study of wind pressures on a single-family dwelling in model and full scale. Journal of Wind Engineering and Industrial Aerodynamics 1: 177-199.

9. Apperley L, Surry D, Stathopoulos T, et al. (1979) Comparative measurements of wind pressure on a model of a full-scale experimental house at Aylesbury, England. Journal of Wind Engineering and Industrial Aerodynamics 4: 207-228.

10. Richardson GM and Surry D (1991) Comparisons of wind-tunnel and full-scale surface pressure measurements on low-rise pitched-roof buildings. Journal of Wind Engineering and Industrial Aerodynamics 38: 249-256.

11. Tieleman WH (1992) Pressures on surface-mounted prisms: the effects of incident turbulence. Journal of Wind Engineering and Industrial Aerodynamics 49: 289-300.

12. Tieleman WH (1992) Problems associated with flow modelling procedures for low-rise structures. Journal of Wind Engineering and Industrial Aerodynamics 41: 923-934.

13. Levitan ML and Mehta KC (1992) Texas Tech field experiments for wind loads part 1: building and pressure measuring system. Journal of Wind Engineering and Industrial Aerodynamics 43(1): 1565-1576.

14. Levitan ML and Mehta KC (1992) Texas tech field experiments for wind loads part II: meteorological instrumentation and terrain parameters. Journal of Wind Engineering and Industrial Aerodynamics 43(1): 1577-1588.

15. Richardson GM and Blackmore PA (1995) The Silsoe Structures Building: Comparison of 1:100 model-scale data with full-scale data. Journal of Wind Engineering and Industrial Aerodynamics 57: 191-201.

16. Dalley S (1996) Surface pressure spectra on a model of the Silsoe structures building and comparison with full-scale. Journal of Wind Engineering and Industrial Aerodynamics 60: 177-187.

17. Geurts CPW (1996) Full-scale and wind-tunnel measurements of the wind and wind-induced pressures over suburban terrain. Journal of Wind Engineering and Industrial Aerodynamics 64: 89-100. 
18. Hoxey RP, Robertson AP, Richardson GM, et al. (1997) Correction of wind-tunnel pressure coefficients for Reynolds number effect. Journal of Wind Engineering and Industrial Aerodynamics 69: 547-555.

19. Richardson GM, Hoxey RP, Robertson AP, et al. (1997) The Silsoe Building: Comparisons of pressures measured at full scale and in two wind tunnels. Journal of Wind Engineering and Industrial Aerodynamics 72: 187-197.

20. Hoxey RP, Reynolds AM, Richardson GM, et al. (1998) Observations of Reynolds number sensitivity in the separated flow region on a bluff body. Journal of Wind Engineering and Industrial Aerodynamics 73: 231-249.

21. Richards PJ, Hoxey RP, and Short LJ (2001) Wind pressures on a $6 \mathrm{~m}$ cube. Journal of Wind Engineering and Industrial Aerodynamics 89: 1553-1564.

22. Richards PJ and Hoxey RP (2006) Flow reattachment on the roof of a $6 \mathrm{~m}$ cube. Journal of Wind Engineering and Industrial Aerodynamics 94: 77-99.

23. Kasperski M and Hoxey R (2008) Extreme-value analysis for observed peak pressures on the Silsoe cube. Journal of Wind Engineering and Industrial Aerodynamics 96: 994-1002.

24. Liu Z, Prevatt DO, Aponte-Bermudez LD, et al. (2009) Field measurement and wind tunnel simulation of hurricane wind loads on a single family dwelling. Engineering Structures 31: 2265-2274.

25. Dalgliesh WA, Wright W, and Schriever WR (1967) Wind pressure measurements on a full-scale high-rise office building. Proceedings of international research seminar on wind effects on buildings and structures, Ottawa.

26. Dalgliesh WA (1969) Experience with wind pressure measurements on a full-scale building. Proceedings of technical meeting concerning wind loads on buildings and structures, Gaithersburg, Maryland.

27. Dalgliesh WA (1975) Comparison of model/full-scale wind pressures on a high-rise building, Journal of Industrial Aerodynamics 1: 55-66.

28. Dalgliesh WA and Rainer JH (1978) Measurements of wind induced displacements and accelerations of a 57 -story building in Toronto, Canada. Proceedings of the 3rd colloquium on industrial aerodynamics, Aachen, Germany.

29. Dalgliesh WA, Templin JT, and Cooper KR (1979) Comparisons of wind tunnel and full-scale building surface pressures with emphasis on peaks. Proceeds of the 5th International Conference on Wind Engineering, Fort Collins, Colorado.

30. Dalgliesh WA, Cooper KR, and Templin JT (1983) Comparison of model and full-scale accelerations of a high-rise building. Journal of Wind Engineering and Industrial Aerodynamics 13: 217-228.

31. Li QS, Xiao YQ, Wong CK, et al. (2004) Field measurements of typhoon effects on a super tall building. Engineering Structures 26: 233-244.

32. Li QS, Xiao YQ, and Wong CK (2005) Full-scale monitoring of typhoon effects on super tall buildings. Journal of Fluids and Structures 20: 697-717.

33. Li QS, Fu JY, Xiao YQ, et al. (2006) Wind tunnel and full-scale study of wind effects on China's tallest building. Engineering Structures 28: 1745-1758.

34. Li QS, Xiao YQ, Fu JY, et al. (2007) Full-scale measurements of wind effects on the Jin Mao building. Journal of Wind Engineering and Industrial Aerodynamics 95: 445-466.

35. Li QS, Xiao YQ, Wu JR, et al. (2008) Typhoon effects on super-tall buildings. Journal of Sound and Vibration 313: 581-602.

36. Fu JY, Li QS, Wu JR, et al. (2008) Field measurements of boundary layer wind characteristics and wind-induced responses of super-tall buildings. Journal of Wind Engineering and Industrial Aerodynamics 96 : 1332-1358.

37. Fu JY, Wu JR, Xu A, et al. (2012) Full-scale measurements of wind effects on Guangzhou West Tower. Engineering Structures 35: 120-139.

38. Yi J and Li QS (2015) Wind tunnel and full-scale study of wind effects on a super-tall building. Journal of Fluids and Structures 58: 236-253.

39. Kato N, Niihori Y, Kurita T, et al. (1997) Full-scale measurement of wind-induced internal pressures in a high-rise building. Journal of Wind Engineering and Industrial Aerodynamics 69: 619-630.

40. Lim KEW, Watkins S, Clothier R, et al. (2016) Full-scale flow measurement on a tall building with a continuous-wave Doppler Lidar anemometer. Journal of Wind Engineering and Industrial Aerodynamics 154: 69-75.

41. Delaunay D and Grillaud G (1998) Field measurements of the wind-induced response of a cable stayed bridge: Validation of previsional studies. Journal of Wind Engineering and Industrial Aerodynamics 74: 883-890.

42. Frandsen JB (2001) Simultaneous pressures and accelerations measured full-scale on the Great Belt East suspension bridge. Journal of Wind Engineering and Industrial Aerodynamics 89: 95-129.

43. Xu YL and Zhu LD (2005) Buffeting response of long-span cable-supported bridges under skew winds. Part 2: case study. Journal of Sound and Vibration 281: 675-697.

44. Li H, Laima S, Zhang Q, et al. (2014) Field monitoring and validation of vortex-induced vibrations of a long-span suspension bridge. Journal of Wind Engineering and Industrial Aerodynamics 124: 54-67.

45. Chen F, Li QS, Wu JR, et al. (2011) Wind effects on a long-span beam string roof structure: Wind tunnel test, field measurement and numerical analysis. Journal of Constructional Steel Research 67: 1591-1604.

46. Chen B, Wu T, Yang Y, et al. (2016) Wind effects on a cable-suspended roof: Full-scale measurements and wind tunnel based predictions. Journal of Wind Engineering and Industrial Aerodynamics 155: 159-173. 
47. Pirner M (1982) Wind pressure fluctuations on a cooling tower. Journal of Wind Engineering and Industrial Aerodynamics 10: 343-360.

48. Cheng XX, Zhao L, Ge YJ, et al. (2015) Wind pressures on a large cooling tower. Advances in Structural Engineering 18(2): 201-220.

49. Cheng XX, Zhao L, Ge YJ, et al. (2016) Wind effects on rough-walled and smooth-walled large cooling towers. Advances in Structural Engineering Article ID 1369433216664354.

50. Cheng XX, Dong J, Peng Y, et al. (2017) A study of non-stationary wind effects on a full-scale large cooling tower using empirical mode decomposition. Mathematical Problems in Engineering Article ID 9083426, 15 pages.

51. Pang JB (2006) Observation and wind tunnel simulation of strong wind characteristics in coastal and mountainous areas. Doctoral Dissertation, Tongji University, Shanghai (in Chinese).

52. Farell C and Iyengar AKS (1999) Experiments on the wind tunnel simulation of atmospheric boundary layers. Journal of Wind Engineering and Industrial Aerodynamics 79(1): 11-35.

53. Lin SC and Wang CA (1972) Decay of isotropic turbulence generated by a mechanically agitated grid. The Physics of Fluids 15: 1363-1369.

54. Cermak JE and Peterka JA (1978) Wind Engineering Applications to Civil Engineering. ASCE Convention and Exposition, Chicago.

55. Cermak JE (1987) Advances in physical modeling for wind engineering. Journal of Engineering Mechanics, ASCE 113(5): 737-756.

56. Cermak JE (1995) Progress in physical modeling for wind engineering. Journal of Wind Engineering and Industrial Aerodynamics 54: 439-455.

57. Cermak JE and Cochran LS (1992) Physical modeling of the atmospheric surface layer. Journal of Wind Engineering and Industrial Aerodynamics 41: 935-946.

58. Cermak JE, Cochran LS, and Leffler RD (1995) Wind tunnel modeling of the atmospheric surface layer. Journal of Wind Engineering and Industrial Aerodynamics 54: 505-513.

59. Kobayashi H and Hatanaka A (1992) Active generation of wind gust in a two-dimensional wind tunnel. Journal of Wind Engineering and Industrial Aerodynamics 42: 959-970.

60. Kobayashi H, Hatanaka A, and Ginsing NJ (1994) Direct measurement of buffeting wind forces on bridge decks. Journal of Wind Engineering and Industrial Aerodynamics 53: 315-330.

61. Diana G, Bruni S, and Cigada A (2002) Complex aerodynamic admittance role in buffeting response of a bridge deck. Journal of Wind Engineering and Industrial Aerodynamics 90: 2057-2072.

62. Diana G, Rocchi D, Argentini T, et al. (2010) Aerodynamic instability of a bridge deck section model: linear and nonlinear approach to force modeling. Journal of Wind Engineering and Industrial Aerodynamics 98: 363-374.

63. Cigada A, Diana G, and Zappa E (2002) On the response of a bridge deck to turbulent wind: a new approach. Journal of Wind Engineering and Industrial Aerodynamics 90: 1173-1182.

64. Kareem A and $\mathrm{Wu} \mathrm{T}$ (2013) Wind-induced effects on bluff bodies in turbulent flows: Nonstationary, non-Gaussian and nonlinear features. Journal of Wind Engineering and Industrial Aerodynamics 122: 21-37.

65. Nishi A, Miyagi H, and Higuchi K (1993) A computer-controlled wind tunnel. Journal of Wind Engineering and Industrial Aerodynamics 46: 837-846.

66. Nishi A, Kikugawa H, Matsuda Y, et al. (1997) Turbulence control in multiple-fan wind tunnels. Journal of Wind Engineering and Industrial Aerodynamics 67: 861-872.

67. Nishi A, Kikugawa H, Matsuda Y, et al. (1999) Active control of turbulence for an atmospheric boundary layer model in a wind tunnel. Journal of Wind Engineering and Industrial Aerodynamics 83: 409-419.

68. Nishi A and Miyagi H (1995) Computer-controlled wind tunnel for wind-engineering applications. Journal of Wind Engineering and Industrial Aerodynamics 54: 493-504.

69. Cao S, Nishi A, Hirano K, et al. (2001) An active controlled wind tunnel and its application to the reproduction of the atmospheric boundary layer. Boundary-Layer Meteorology 101: 61-76.

70. Cao S, Nishi A, Kikugawa H, et al. (2002) Reproduction of wind velocity history in a multiple fan wind tunnel. Journal of Wind Engineering and Industrial Aerodynamics 90: 1719-1729. 